\title{
OBSERVACIONES FILOSÓFICAS A PROPÓSITO DEL MANIFIESTO FUNDACIONAL DE LA ESCUELA DE METAFÍSICA DE MADRID
}

\section{PHILOSOPHICAL OBSERVATIONS ON THE PURPOSE OF THE FUNDATIONAL MANIFESTO OF THE SCHOOL OF METAPHYSICS OF MADRID}

FRANCISCO LEÓN FLORIDO

Universidad Complutense de Madrid

\section{RESUMEN}

En este artículo de reflexión filosófica pretendemos presentar de forma comentada los nueve artículos que componen el Manifiesto Fundacional de la Escuela de Metafísica de Madrid. A través de este comentario filosófico a dichos artículos el autor va presentando, a su vez, una forma de entender y comprender la metafísica que responda a la cuestión ¿qué es la metafísica?, como proyecto para el tiempo presente.

Palabras clave: Escuela de Metafísica de Madrid, metafísica, filosofía

\section{ABSTRACT}

In this paper of philosophical reflection, we intend to present in an annotated way the nine articles that make up the Foundational Manifesto of the School of Metaphysics of Madrid. Through this philosophical commentary on these articles, the author is presenting, in turn, a way of understanding the metaphysics that answers the question, what is metaphysics? as a project for the present time. 
Keywords: School of Metaphysics of Madrid, metaphysics, philosophy.

Recientemente ha visto la luz el Manifiesto Fundacional de la "Escuela de Metafísica de Madrid". En esta breve reseña nos proponemos exponer algunas dispersas observaciones filosóficas relativas a los nueve artículos que componen este escrito germinal.

1. Que nos sentimos concernidos ante la pérdida de sustantividad y la disgregación de la filosofía, entendida como el primero de los saberes y fundamento de todas las formas de pensamiento.

Hasta bien entrada la época moderna se ha considerado que las doctrinas metafísicas constituyen el núcleo que permite comprender las soluciones que los diversos sistemas filosóficos dan a los principales problemas que se plantean. Para representar la filosofía, Descartes, el primer pensador moderno, utiliza la imagen de un árbol, cuyas raíces están constituida por los principios metafísicos, de los que se alimenta el gran tronco que es la física, cuyas ramas son la mecánica y la medicina, y que da sus frutos más preciosos en la moral. Sobre todo, tras la crítica positivista al papel de la metafísica como opuesta al verdadero conocimiento científico, se ha tendido a desacreditar la función cognoscitiva de esta disciplina, que ha sido sustituida por en gran medida por la teoría de la ciencia, o por la simple desaparición de un intento integrador de las diversas ciencias particulares. Desde esta perspectiva, hay que entender la predilección por la interdisciplinaridad, por la síntesis de conocimientos procedentes de diversos campos, como una muestra de la nostalgia de un saber unificado, como el que ofrecía la metafísica tradicional.

Pese a este esfuerzo interdisciplinar, lo cierto es que las ciencias particulares no han hecho sino acentuar su disgregación, a medida que sus procedimientos se han ido haciendo más específicos y sus resultados han ido ampliándose. Para comenzar, es preciso reconocer que nunca en la historia del pensamiento occidental ha sido mayor la separación entre las ciencias físico-matemáticas y los saberes humanísticos, a pesar de los intentos de estos últimos por asimilarse a los métodos y procedimientos de aquéllas. Esta desalentadora situación promueve un escepticismo generalizado, aunque quizá el interés contemporáneo por los problemas del lenguaje científico podría servir como punto de conexión

1 Vicente Llamas Roig, "Manifiesto Fundacional Escuela de Metafísica de Madrid", Carthaginensia, Revista de Estudios e Investigación. 35 (2019): 251-252. 
con el antiguo ideal aristotélico de la metafísica como ciencia humana del lenguaje.

Nuestro tiempo se caracteriza por el predominio del denominado "pensamiento débil", que ha anunciado el nacimiento de una nueva época que habría de suceder al momento del "final de la metafísica". Se trata del último momento de un viaje intelectual que se desarrolló a lo largo del siglo pasado en el que se ha completado la renuncia a los principios instaurados por el pensamiento moderno para sustituir a los que antes había creado la tradición greco-cristiana, una renuncia que se hizo más evidente después del último intento por parte del formalismo logicista por abrir el espacio del lenguaje científico para dirimir la batalla de la reconstrucción de lo humano. Se trataba de retornar a los orígenes del proyecto ilustrado en el que se vislumbraba el progreso en el doble sentido del horizonte histórico y del horizonte científico, dos ramas que brotaban del mismo árbol de la Ilustración, de modo que se procuró hacer reverdecer la rama científica que había sido relegada por el irracionalismo vitalista y nihilista. La gramática lógica del primer Wittgenstein y los protocolos científicos de los neopositivistas pueden considerarse como los dos grandes intentos del formalismo científico por superar el historicismo "idealista" del siglo XIX. La unidad de la realidad y el conocimiento, que la lógica formal creyó poder dar por supuesta hasta que Russell hizo entrar en crisis el ideal de la axiomatización científica, se transformó en un problema cada vez más acuciante. Por ello, las corrientes que habían arruinado la vieja unidad greco-cristiana del ser y del saber se vieron en la necesidad de reconstruir esta unidad enfrentados a las paradojas lógicas, a la incertidumbre gnoseológica, a la equivocidad de los usos particulares del lenguaje y a la fuerza centrífuga de las irreprimibles singularidades pasionales. La consecuencia fue la aparición de diversas corrientes que apuntaban en la misma dirección desde diferentes campos del saber: las filosofías del final de la era metafísica, la concepción socio-histórica del "final de la historia", la teoría hermenéutica de la deconstrucción del lenguaje o el "discurso contra el método" científico positivista. Se impuso así la conclusión de que, puesto que el conocimiento no puede justificar la universalidad de sus principios, sólo cabe renunciar definitivamente a intentar esta justificación. Se aceptó entonces la existencia de una "razón débil" construida con los fragmentos de todos los discursos, que ya no soportan verse subordinados a los principios de la Razón en su sentido fuerte. 
2. Que reconocemos que en todas las etapas de la historia de la filosofia, desde sus orígenes griegos hasta la actualidad, en diversa medida, se ha elaborado una forma de pensamiento metafisico que ha permitido a cada época entender y explicar la realidad mundana y humana.

La historia de la filosofía es un campo muy transitado por los investigadores, de entre los cuales unos se han inclinado más a destacar sus aspectos "históricos", en el sentido de entender que se trataría ante todo de mostrar las aportaciones doctrinales de cada autor en relación con su biografía y el contexto doctrinal y cultural de su época, mientras que otros intérpretes se inclinan más por una explicación "filosófica", que pone de relieve que cada pensamiento forma parte de un esfuerzo universal de la razón humana por conocer la verdad y definir el bien. Desde el reconstructivismo analítico anglosajón a la historia de las mentalidades francesa, de la philosophia perennis a la historia de los sistemas, las diversas corrientes apuestan por una u otra interpretación. Sería necesario hacer justicia a las dos perspectivas, no con ánimo ecléctico, sino al entender que las dos líneas son el resultado de las posibilidades abiertas por la actividad concreta de la inteligencia humana que se expresa en las grandes doctrinas de pensamiento. Para ello no se debe separar la lógica del conocimiento de los contenidos doctrinales. También lo es hallar el modo de conciliar la aspiración a la unidad del saber más allá de los avatares históricos con el necesario reconocimiento de los cambios y las rupturas entre las diversas escuelas que coexisten en una época y las que se suceden a veces en manifiesta oposición. Un modo de afrontar esta tarea, habría, creemos, de integrar dos elementos: (1) la estructura de los conceptos filosóficos, que presentan una relativa variabilidad de una época a otra y de una escuela a otra, sobre un fondo estructural común, que es el precipitado de procesos históricos no arbitrarios; (2) la génesis de los conceptos filosóficos, en que se mostrarían las circunstancias concretas, psicológicas, históricas y culturales, las polémicas y los acuerdos, que influyeron en la formación de las filosofías y en su evolución. De este modo podría trasladarse isomórficamente la historia de la filosofía la relación entre forma y contenido que caracterizaba a la relación preconstitutiva aristotélica: por un lado, los cambios que tienen lugar en el significado de los conceptos utilizados y la forma en que se organizan, y por otro, la estabilidad y permanencia de un fondo estructural común que respondería a los grandes interrogantes filosóficos: el tipo de causalidad que se defiende, la solución al problema de la relación entre unidad y multiplicidad, la conexión que se establece entre lenguaje y realidad, la clase de relación que se da entre el sujeto y el mundo, etc. 
La historia de la filosofía debe sacar a la luz el orden y sistema de las filosofías, respetando, no obstante, su esencial diversidad. La labor del historiador de la filosofía será, entonces, doble: por un lado, debe exponer con la mayor exactitud filológica y textual los temas de cada filosofía, $y$, por otro, ejercer una labor interpretativa y crítica, analizando la estructura conceptual que se despliega en cada forma de pensamiento, escuela, autor o corriente. La historia de la filosofía es, ante todo, una actividad, no un depósito donde se archivan los sistemas del pasado. Por ello, no se trata de un saber acumulativo, sino que cada generación está obligada a reemprender la labor de apropiación de la tradición filosófica

3. Que entendemos la metafísica como la forma primera y radical de expresión racional que responde al deseo de conocimiento de la totalidad de las cosas.

El ser humano, como cualquier otro animal dotado de sentidos, se ve atraído por la multitud de sensaciones que le ofrecen, pero, a diferencia del resto de los animales, él es el único que se interroga acerca del origen y las cualidades del mundo que le rodea. La sabiduría filosófica trata de responder a estas preguntas, y para ello la inteligencia genera una serie de conceptos que son las primeras respuestas a las preguntas más generales o universales que la inteligencia humana se hace ante las cosas del mundo: ¿de qué está hecho? (causa material), ¿qué es? (causa formal), ¿qué o quién lo hizo? (causa eficiente), ¿para qué se ha hecho? (causa final). Al responder a estas preguntas se generan conceptos como los de materia, forma, potencia, acto, sustancia, accidente, etc. que constituyen el objeto de investigación de la ciencia de los principios del mundo. Todas estas cuestiones pueden, finalmente, resumirse en una pregunta: ¿qué es el ser?, pues ser, es decir, que son o existen, es lo que tienen absolutamente en común todas las cosas.

La metafísica ha de ser una ciencia humana, que pueda alcanzar el máximo rigor y exactitud que les son dados alcanzar al hombre, cuya fuente básica de conocimiento no es la intuición intelectual de la verdad perfecta, sino la percepción sensible de las cosas múltiples, cambiantes y confusas tal como aparecen a los sentidos. Desde estos supuestos, Aristóteles entiende que la respuesta inmediata a la pregunta metafísica por excelencia: ¿qué es el ser? no puede ser otra que: el ser se dice de muchas maneras. Esta respuesta nos pone sobre la pista de las dos notas básicas de la concepción aristotélica de la metafísica como saber humano. La metafísica se muestra como una ciencia del lenguaje, del decir humano, y como un saber múltiple, que no trata de reducir artificialmente a la unidad una realidad que en sí misma es diversa. Por tanto, la metafísica se 
constituye como una ciencia del lenguaje, de los modos que tiene el decir humano para aprehender intelectualmente la realidad a partir de los datos que le suministran los sentidos. Con ello, se abandona el ideal unívoco platónico, y se reconoce que la lógica de la ciencia humana tiene que hacer justicia a la multiplicidad esencial de lo real. Pero, entonces, se correría fácilmente el riesgo de caer en la equivocidad, esto es, en la pluralidad indefinida de significados de las palabras, dependiendo de la situación en que aparecen las cosas al conocimiento, lo que imposibilitaría la ciencia, que siempre busca establecer significaciones únicas. Situado ante la alternativa de una ciencia unívoca perfecta, pero sobrehumana, y un saber equívoco, múltiple y humano, pero no científico, Aristóteles busca una tercera solución: la ciencia de la que trata ha de utilizar una lógica analógica, es decir, debe atribuir significaciones a las palabras buscando la unidad en la diferencia. Así, la metafísica quedaría definida como una ciencia analógica sobre la pluralidad de significaciones que ofrece el término ser al conocimiento empírico humano. Lo característico del conocer humano es su pluralidad, debido a su origen empírico, por estar sometido a las condiciones que imponen los sentidos. Pero, el saber científico busca la unidad en lo múltiple, y para ello cuenta con una característica esencial de la inteligencia humana, que es su capacidad para encontrar similitudes entre cosas diferentes. Así es como puede constituirse una ciencia que respete los límites del conocimiento humano, sin renunciar al ideal de la exactitud, de modo que la metafísica, entendida como una ciencia a nivel humano, hace uso de los recursos de la analogía y trata de determinar lo que tienen en común las múltiples significaciones del ser. Con ello queda definido el marco en que se desarrollarán las doctrinas metafísicas siguiendo el hilo de los intereses históricos y el debate entre los sistemas filosóficos.

4. Que creemos necesario impulsar, desde el reconocimiento de la propia tradición filosófica, un espacio de discusión metafísica capaz de responder a la problemática que entraña el estudio de la naturaleza íntima de la realidad que se nos presenta.

La crítica a la tradición filosófica ha incidido en su diversidad de posiciones, a veces contradictorias, lo que parece dificultar extraordinariamente la búsqueda de un sentido unitario en la sucesión de los diversos sistemas de pensamiento. Las grandes cuestiones metafísicas: las formas de la causalidad, las relaciones entre la materia y la forma, entre el cuerpo y el espíritu, entre el yo y el mundo, etc., han ido presentando configuraciones diversas en las distintas filosofías. No obstante, a esa diversidad histórica o genética, le corresponde un cierto sentido 
unitario desde el punto de vista estructural, según el modo en que se organizan y definen los conceptos filosóficos en cada doctrina y autor. Frente a una concepción reduccionista del estudio de la tradición filosófica, Gadamer propone la Wirkungsgeschichte, una historia de los contenidos efectivos que suministra la tradición. Se trata de negar la posibilidad de imponer a las concepciones tradicionales unas formas conceptuales que definirían desde la actualidad más lo que debió haber sido que lo que efectivamente fue. Desde este punto de vista, el significado mismo del "método" habría de ser cuestionado. Sabemos que el sentido habitual que el pensamiento moderno atribuye al método es el de una guía única de la verdad, siguiendo la estela cartesiana. Esta noción se ha hecho tan universal, que ya no se percibe que ella misma es el resultado de un proceso histórico, en el que unas posiciones no son sin más sustituidas por otras, sino que pueden convivir al menos en los rastros que han dejado en las doctrinas dominantes.

En cierto sentido, recogiendo parcialmente los resultados del pensamiento ilustrado y postilustrado, la ética discursiva propone identificar tres procesos que discurren en la dirección de la libertad: la historia del saber (Kant) = la historia de la cultura racional (Hegel) = la historia de la emancipación (Marx). La dificultad de conciliar estas tres formas de devenir histórico tan diversas es evidente, aunque todas puedan considerarse partícipes de un mismo proyecto ilustrado. Para conseguirlo, las nuevas éticas consideran que el instrumento adecuado es la comunicación, entendida como diálogo entre seres racionales cuyo fin es lograr el consenso, en el convencimiento de que con ello se acabará por constituir una "comunidad ideal de diálogo" y, por tanto, una sociedad libre, ya sea en su sentido socialista (Habermas) o en su sentido liberal (Rawls).

El "naturalismo" aristotélico se expresa en todas las ramas teóricas en las que subyace siempre la unidad de la naturaleza, que impone límites que no pueden ser rebasados. La naturaleza se presenta como un espacio continuo común sobre el que han de darse las diferentes perspectivas formales que el intelecto humano desarrolla en sus diferentes actividades y disciplinas. En la ética, la célebre determinación del "término medio" es una clara muestra de la presencia de la unidad natural, que adopta la forma de un continuo ético espacial análogo al que se da en el mundo físico. Como la matemática es una ciencia meramente subjetiva, es decir, un procedimiento cómodo de medir una realidad cuya complejidad cualitativa escapa a la simple exactitud cuantitativa, cuando se aplica al ámbito moral no existe un patrón de medida dado, por lo que ha de ser el phronimos, mediante sus elecciones concretas, quien provea de las formas necesarias para delimitar formalmente el complejo mundo de los actos humanos. Es este modelo de sabiduría humana quien concluye el movimiento hacia las formas 
definidas del bien que la naturaleza por sí misma realiza, pero sólo potencialmente, pues la naturaleza ya tiende al bien, aunque requiera del artificio humano para perfeccionarse. Para Aristóteles, tanto la ética como la política son formas intelectuales mediante las que el hombre empuja los límites que ha trazado la naturaleza un poco más allá, pues la naturaleza intelectual humana no se conforma con el bien preconstituido en el mundo natural.

\section{Que la metafísica es una actividad dialógica.}

La necesidad de suponer una potencia exterior que ordene el proceso ético hace que, pese a las constantes apelaciones a la autonomía de los principios éti$\cos$, hoy se requiera la intervención de una administración estatal cuya función es poner en movimiento a la sociedad en pos del ideal utópico que las nuevas éticas proponen. El Estado habría de encargarse de organizar administrativamente el diálogo universal regido por las normas procedimentales del racionalismo discursivo. Es el Estado el dios racional de las éticas del discurso, con poder para reprimir adecuadamente a los enemigos del diálogo. Para que el diálogo se realice del modo adecuado al objetivo del consenso, el sujeto racional debe transformarse en un sujeto dialogante. Sin embargo, importantes movimientos intelectuales, del neoestructuralismo al deconstructivismo, han insistido en justificar teóricamente la tesis de la desaparición del sujeto y la consiguiente diseminación de los discursos sobre un plano social vacío, indiferente a los transvases microfísicos del poder. Por este motivo, buena parte del trabajo realizado por las éticas comunicativas y procedimentales ha estado encaminado a recuperar la noción de sujeto en el horizonte de la fundamentación ética de las sociedades democráticas complejas. El sujeto liberal (Rawls), el sujeto irónico (Rorty) o el sujeto comunicativo (Apel-Habermas) son algunas de las diferentes formas que ha adoptado este intento teórico, que ha dado como resultado la construcción de la imagen de un nuevo sujeto dotado de capacidad de diálogo, justo y equitativo, cuya acción se orienta hacia el acuerdo social. Éste es el sujeto discursivo-liberal que se impone como modelo ideal del ciudadano en las democracias avanzadas.

Nada en apariencia más "razonable" y "moralizante", que este sujeto ideológicamente "débil" frente al sujeto doctrinalmente "fuerte" de las tradiciones procedentes del fanatismo religioso o político. Pero, pese a la unanimidad con que hoy se acoge esta nueva figura de lo humano, la ética y la filosofía política se encuentran aún ante la tarea de ejercer la crítica a partir de la comprensión de los principios y consecuencias de estas doctrinas socio-políticas, que exhiben su neutralidad que justifican en su búsqueda de la igualdad y la formalidad 
absolutas. Sin embargo, una crítica desde la ética filosófica, como la que aquí proponemos, creemos que puede hacer comprender cómo el carácter ideológico subyacente a las éticas del consenso "débil" las pone necesariamente al servicio de una concepción determinada del Estado que surge de la evolución desde la forma primitiva del Estado de derecho, a la forma clásica del Estado del bienestar, para concluir en una nueva forma sistémica del Estado del bienestar basado en la compensación. Desde este punto de vista, la "sociedad ideal de comunicación" no sería más que una imagen utópica que no se corresponde con la situación de hecho de las sociedades actuales, que son sistemas comunicativos indiferentes a las virtualidades de la democracia participativa, el diálogo universal o el consenso igualitario.

6. Que el discurso metafisico sólo es posible en un espacio comunitario que admita la libertad de pensamiento y expresión.

Ya desde sus orígenes griegos, el discurso científico-demostrativo reclamó el más alto grado de acuerdo y universalidad, precisamente porque es el discurso mediante el que la comunidad (koinônia) se identifica a sí misma en su posición de ser. Por eso, en la estructura aristotélica, el acuerdo universal es necesariamente previo al discurso, al diálogo, que tendría como misión únicamente reforzar el consenso, al hacer posible la divergencia de teorías (discurso dialéctico) de intereses (discurso forense) o de opiniones (discurso asambleario) desde la unidad que se recupera posteriormente en el consenso final. Por consiguiente, el acuerdo se encuentra antes y después, como posición de partida y conclusión del diálogo. En la concepción aristotélica del diálogo el acuerdo se da sobre el todo (que es en ese sentido un universal), lo que implica que hay un hilo de unidad que se mantiene a través de las diferencias entre las partes. La asamblea, el jurado o la comunidad de los sabios, sujetos de la retórica y la dialéctica, las dos ciencias del diálogo aristotélico, señalan un campo de discusión no formalmente predeterminado, que apunta hacia el acuerdo dentro de los límites ya presupuestos de antemano: la verdad en el debate científico entre los sabios, la utilidad civil en la asamblea o la determinación de los hechos que sucedieron y la equidad en el jurado.

La ética comunicativa contemporánea se sitúa ante el diálogo en una posición estructural muy distinta. La distinción formal aplicada al diálogo supone la aparición de dos sujetos monólogicos que se comunican con intención de consenso. Aparentemente, el esquema que sigue el diálogo moderno es el mismo que el planteado por Aristóteles, pues también se parte de un consenso inicial de los sujetos sobre los procedimientos del proceso dialógico y se concluye en 
un consenso final sobre las conclusiones. Sin embargo, los modernos distinguen formalmente las tres fases del diálogo procedimientos / diálogo / consenso, que estaban unidas analógicamente en el aristotelismo, y no establecen entre ellas relaciones intencionales que las vinculan por tener un fin común activo-práctico compartido por los sujetos que dialogan.

Las éticas del consenso débil se empeñan en justificar teóricamente el cumplimiento de los ideales democráticos, pues, por un lado, defienden la posibilidad de la libertad de los individuos que ya no están sometidos a la constricción de las tradiciones religiosas, ideológicas, culturales, etc. y pueden crear indeterminadamente las normas que han de regir su convivencia social, y, por otro, despliegan su capacidad teórica para establecer un entramado de normas que puedan justificar la existencia de la igualdad en la situación originaria, en la que todos tendrían acceso en las mismas condiciones a una posición en el diálogo y todos verían satisfechas al final al menos una parte de sus demandas. De la fuerza de este modelo habla bien a las claras el hecho de que las actuales sociedades democráticas, que son administradas según el paradigma del Estado sistémico del bienestar, se hayan acabado transformando en sistemas sociales cuya fuerza reside en la garantía de supervivencia que proviene del hecho de que son capaces de regenerarse exclusivamente con sus mecanismos internos, eliminando las incertidumbres que amenazaban a otras formas de Estado que se enfrentaban a alternativas externas que resultaban ser un contrapoder latente.

Las tradicionales ideologías políticas antiestatales: el comunismo, el anarquismo, el socialismo libertario, etc., han sufrido un proceso de declinación, y nuevas ideologías tratan de aglutinar los principales elementos de las formas de pensamiento social tradicionales, desde el liberalismo a la política de los derechos, y desde el comunismo a las diversas formas de socialismo libertario, para proporcionar la unidad ideológica imprescindible al nuevo modelo del sistema social en un Estado del bienestar. La utopía parece por fin hecha realidad, cuando disponemos de un Estado democrático de ciudadanos libres e iguales, administrados con el objetivo de corregir las desigualdades, que sólo tiene ante sí el reto de extender universalmente sus principios a zonas geográficas o sectores sociales en los que "aún no" ha penetrado.

Esta situación de aparente placidez convive, sin embargo, con una reacción en ciertos niveles sociales, étnicos y culturales, que podríamos calificar como de "malestar en el bienestar". Pues, si, por un lado, la pluralidad y la diversidad, el diálogo, la libertad y los derechos, la tolerancia y la bonhomía se imponen como modelo universal de la administración estatal global, por otro, aparecen con fuerza creciente tendencias disgregadoras, particularistas, reivindicadoras 
de tradiciones, incluso precivilizadas, que rechazan la participación o el diálogo. Provincialismos, regionalismos y nacionalismos reivindican sus principios frente a los de un Estado "central" al que sitúan en el papel del "otro". Las Naciones Unidas, que representan el espacio para el diálogo mundial, aparecen alternativamente en su papel de "policía mundial" o como el espacio para el enfrentamiento de intereses nacionales que sólo se apelan al diálogo si les es beneficioso coyunturalmente. La Unión Europea inaugura vías abiertas para el comercio, pero no encuentra el modo de superar las suspicacias y los viejos conflictos que han dejado abiertos siglos de historia marcados por el enfrentamiento entre las naciones en el viejo continente. Pueblos enteros hacen de sus creencias religiosas una bandera para oponerse violentamente a la penetración de ideologías y formas culturales que consideran un símbolo de la opresión. En fin, en las sociedades democráticas occidentales, la tolerancia ante la diversidad pierde a menudo su carácter positivo para tornarse "atolerancia" indiferente ante el crecimiento de las pequeñas reivindicaciones, de la reclamación ilimitada de derechos particulares, ante la saturación de productos ideológicos de consumo promovidos por los medios de comunicación que dejan de ser un medio para la reflexión para transformarse en un campo abierto a la expresión exacerbada de los sentimientos, indiferentemente grandiosos o sórdidos.

7. Que nuestra época se caracteriza por la subordinación del pensamiento filosófico y metafísico a la ideología en una extrema pluralidad de formas.

La crisis de la racionalidad ha traído consigo la percepción del final tanto de las ideologías dominantes en los siglos anteriores y de los ideales socio-políticos que habían contribuido a construir las grandes utopías revolucionarias, como de las concepciones éticas que defendían la existencia de una conciencia moral universal que podía identificarse con el interés de la razón. Así que, paralelamente al triunfo del pensamiento débil en el campo de la teoría del conocimiento, en la teoría ética se ha sentido la necesidad de definir una "ética mínima" capaz de sustituir con éxito tanto a las éticas fuertes de la tradición antigua y medieval como a las éticas universales de los modernos. Se puede decir que el resultado de todos estos movimientos intelectuales ha sido la generalización de la ecuación debilidad de la razón metafísica $=$ escepticismo científico $=$ minimalismo ético = pluralismo socio-político. La tendencia a la fragmentación del pensamiento ha acabado incluso por dar lugar a una nueva concepción de la democracia, en la que el "pluralismo" no es sólo el lema de una determinada alternativa política, sino la esencia misma de la democracia de los individuos. La crisis de las grandes ideologías sustentadas en principios metafísicos ha 
provocado un hecho paradójico, pues mientras que, bajo el influjo del positivismo científico, las teorías socio-políticas habían luchado por independizarse de la reflexión ética, ahora, afectadas por la crisis general de legitimidad de la ciencia en el fin de siglo, reclaman nuevos principios de la ética filosófica que debe proponer el modo de reconstruir el orden social desde una voluntad libre, no sometida a fines ni sujeta a un orden normativo determinado. Las teorías políticas del contrato fueron la respuesta moderna a esta reclamación, sin que significara una diferencia esencial si se suponía que la voluntad expresada en el contrato era un arma defensiva ante el miedo a los demás, como supone Hobbes, o si, por el contrario, como cree Rousseau, el contrato no es más que un mecanismo que permite ordenar una cooperación, que de todas maneras, ya está implícita en su naturaleza de los individuos, defendiendo ese espíritu cooperativo de los riesgos consecuentes a la existencia de individuos asociales.

El sistema ideológico que se expande a través de los medios de comunicación de masas actuales asegura su éxito sobre la base de la naturaleza sentimental-fideística del individuo contemporáneo. Los ciudadanos del mundo global son creyentes de una nueva fe, $\mathrm{y}$, sin embargo, a diferencia de lo que ha sucedido históricamente con las prolongadas y a menudo espantosas luchas entre los credos religiosos, la existencia de una diversidad de opiniones que resultaría de la diversidad de los credos ideológicos de los diferentes grupos mediáticos que los representan no es más que superficial, pues los mensajes que se emiten están determinados por una lógica común, como ya fue reconocido por el primer gran teórico de los mass media, Marshall McLuhan, cuando anunció que en el tiempo que se anunciaba «el medio es el mensaje». Hoy, en cumplimiento de la profecía de McLuhan, los medios de comunicación masiva, al margen de sus pretendidas diferencias ideológicas, emiten un mensaje casi idéntico determinado por el funcionamiento de la máquina comunicativa, que es indiferente al contenido racional de los mensajes ideológicos, con tal que contribuyan a facilitar la adhesión inmediata y sin condiciones de las grandes masas de población que constituyen las sociedades indiferenciadas de un mundo globalizado, construido a imagen y semejanza del modelo de sociedad occidental.

Sobre el modelo de la democracia americana se han construido las democracias igualitaristas contemporáneas en cuyo contexto social ha nacido la corrección política (political correctness), que comenzó siendo tan sólo uno de los muchos lemas del marketing político que los cambios en las modas suele arrastrar al olvido con rapidez. Su sentido se limitó inicialmente a la utilización de un lenguaje cortés y eufemístico con las minorías étnicas y con aquellos sectores que pudieran haberse considerado desfavorecidos por causas naturales, sociales o históricas. Pero después ha alcanzado una dimensión tan amplia y profunda 
en relación con los fenómenos culturales, sociales y políticos que afecta a la estrategia política de todas las democracias avanzadas. Los problemas educativos, el cruce de las culturas, las relaciones de pareja o las inclinaciones sexuales, son algunos de entre los muchos asuntos de interés social que aparecen determinados por la necesidad de respetar los dictados de lo políticamente correcto. Esta cuestión, hasta el momento, aún suele ser objeto de un tratamiento superficial que busca más aprovechar el escándalo mediático que promover una reflexión sobre sus causas y sus posibles consecuencias. Por el contrario, en este breve ensayo sostenemos que la corrección política se ha ido transformando paulatinamente en una vasta construcción ideológica que se ha adaptado extraordinariamente bien a las circunstancias de las sociedades democráticas basadas en el diálogo y el consenso, lo que la hace susceptible de un análisis para indagar en sus orígenes y en su contenido filosófico. Se trataría de abordar el papel de esta nueva ideología, no ya desde la perspectiva del análisis sociológico o político inmediato, que roza con lo meramente periodístico, sino desde la aportación que puede hacer la reflexión ética para comprender tanto los motivos que han llevado a la adopción de determinados principios en las democracias actuales como las consecuencias morales y políticas que tiene para la relación entre el individuo y la comunidad. De hecho, el papel de la ética filosófica ha sido especialmente relevante para fundamentar las teorías socio-políticas contemporáneas que intentan establecer los procedimientos y usos tendentes a hacer posible el diálogo abierto como medio para lograr el acuerdo y la estabilidad en sociedades que han alcanzado un alto grado de complejidad.

8. Creemos vivir en una época de preterición del ser, con abandono, no sólo del objeto del pensamiento metafísico, sino de su modo de ejercicio discursivo.

La historia de la filosofía occidental ha sido la suma de las respuestas a esta pregunta primigenia, pero, sólo los griegos trataron de responder desde la propia razón humana, desde la physis o naturaleza en cuyo seno se encuentra el hombre. Muy pronto surgió una desviación de la metafísica hacia la "onto-teología", es decir, hacia la escisión del objeto de la metafísica, el ser, hacia una ciencia del ente mundano y una ciencia del ser supremo, de Dios, que suministra al mundo su ser y sus principios de conocimiento. Ya en Aristóteles había surgido esta división cuando hace del primer motor el primer conocido y primer deseado por todo en el cosmos, pero será la edad media la que consagre este modo dual de abordar la cuestión del ser, separando definitivamente la ciencia de Dios, que alcanza la verdad con la ayuda de la fe, y la ontología mundana, que utiliza los medios naturales del conocimiento humano para alcanzar una verdad siempre 
provisional. Tampoco el pensamiento moderno se ha librado de esta inclinación, que se ha manifestado como "olvido" de la cuestión por el ser, como consecuencia de la tecnificación del pensamiento. El hecho de "la muerte de Dios" que anunciara Nietzsche no ha supuesto el final del dominio de la teología, puesto la revolución científica moderna ha situado el poder técnico humano en el lugar que antes ocupaba la omnipotencia divina. Lo que hoy queda en el olvido, como en el pensamiento teológico medieval, denuncia Heidegger, es la naturaleza en su ser autónomo, independiente de su uso técnico, una naturaleza en la que habita un hombre también hoy fragmentado por las "ciencias humanas".

9. Que impera una ideología pluriforme y multidimensional, determinante de los mensajes que moldean a las sociedades actuales, que imposibilita el ejercicio de un pensamiento metafísico humano y libre, desplegando un control intencionado sobre los individuos que pretenden hacer uso de su razón.

En las sociedades premodernas se pensaba que en el todo social hay unas partes que dominan sobre otras por el orden natural o divino de las cosas, y los primeros teóricos modernos trasladaron el orden jerárquico al dominio del Soberano sobre los súbditos. El progreso social ha transformado esta diferenciación jerárquica unívoca en una diferenciación funcional, con la que el sistema social, que se funda sobre la posibilidad de simplificación de la complejidad, ha querido responder al reto de establecer una organización no jerárquica, lo que equivale a decir, que no reduzca la complejidad creciente de las sociedades contemporáneas al simple esquema binario mandato / obediencia, pues en el sistema es necesario que todos los individuos puedan participar en condiciones de igualdad sin precisar de una pertenencia previa a alguna clase, grupo o casta determinada. Esto supone que la acción del "poder político" ya no puede seguir únicamente la línea recta que va de lo superior a lo inferior, sino que ha de hacerse circular, dando lugar a procesos de control recíproco y retroalimentación entre todos los segmentos sociales. Es de este modo como el sistema social ejerce el "control del control", lo que enfatiza la desaparición del sujeto del control, tanto agente como paciente, al generar un mecanismo por medio del cual el control se controla a sí mismo. Es ésta la última fase en el proceso de desaparición del sujeto, con lo que se logra la máxima estabilidad para el sistema, al anular los elementos "naturales" no susceptibles de simplificación que obligarían al ejercicio asimétrico del poder para lograr el equilibrio social. El sistema político se presenta, entonces, como el modelo que alcanza el objetivo de la máxima estabilidad social por el expediente de la creación de un espacio social "igualitario" por neutro e indiferente, en el que todos los procesos adoptan la forma del 
círculo de la identidad "artificial" con el fin de garantizar la estabilidad que podría ser puesta en peligro por la irrupción de elementos "naturales" extrasistémicos.

Los medios de comunicación no nacieron para la culturización o la reflexión intelectual, una función que ya realizaban las sociedades ilustradas de sabios y eruditos, sino para "crear opinión", para movilizar a las sociedades democráticas en función de los intereses de las clases burguesas que precisaban liberarse de los impedimentos para la expansión de los mercados que suponían las fronteras entre los pueblos, las castas sociales y las diferencias culturales o intelectuales. Esta tendencia se ha ido acelerando en nuestra época, que ha visto cómo el poder de la opinión se ha trasladado a las masas globales e indiferenciadas, lo que sólo ha podido lograrse quitándoselo a las élites aristocráticas, intelectuales o institucionales, para lo cual ha sido preciso crear una nueva ideología dominante al alcance de ese nuevo sujeto social indiferenciado, sin referencias de un pasado que se toma siempre como elitista. Es plenamente coherente con la historia de la razón occidental que unos medios de comunicación destinados a las grandes masas ajenas a la Ilustración ejerzan su dominio sobre estas masas utilizando un saber basado en la creación de una ideología que ha de abrazarse más por el sentimiento que por la reflexión. Este "saber de la opinión" que convierte a los medios en "creadores de opinión pública", no es ya, como lo entendieron los griegos, un conocimiento inestable y, por ello, poco fiable, sino, muy al contrario, el más firme de los saberes, pues su fiabilidad se funda sobre la adhesión incontrovertible de quienes abrazan una nueva fe.

Los filósofos, a partir de la modernidad, han creído que el duelo secular entre la fe y la razón podía resolverse de un modo sencillo: puesto que lo que todos tenemos en común es la razón, mientras que la fe es abrazada sólo por una parte de la sociedad, bastaría con establecer una forma política en que las leyes sean racionales y se garantice que quienes, además, tengan fe puedan desarrollarla libremente. Es éste un supuesto aparentemente muy firme, pero absolutamente falso, pues, lo que sucede es más bien lo contrario: lo que todos compartimos es la fe y sólo una parte cultiva la razón. Esto, que puede parecer chocante, se hizo ya evidente en los teóricos de la ilustración liberal como David Hume, quien denominó belief (creencia) al componente más común de la naturaleza humana, puesto que todo conocer y todo actuar en el ser humano comienza por una especie de fe en la correspondencia entre nuestras representaciones mentales y lo que hay en el mundo, y luego continúa con una espera basada en la fe en que lo que ha de suceder será como lo que ya ha sucedido antes. Se podría pensar que esta clase de fe profana nada tiene que ver con la fe religiosa, pero el antecedente de esta nueva concepción ilustrada de la creencia, como ya antes 
hemos apuntado, estaba en la evolución intelectual de la escolástica cristiana, que se desarrolló hacia una posición fideísta, para oponerse al racionalismo que había acompañado a la recepción de la filosofía griega en el occidente latino. La consecuencia de esta orientación fue que el contenido de la fe cristiana se transformó en una nueva forma de racionalidad, lo que, lejos de concluir en una recaída en formas de superstición paleoreligiosas, tuvo el sano efecto de abrir las puertas a la posibilidad de una revolución científica que habría de acometerse en el renacimiento. El hecho es que, en general, los defensores de la razón ilustrada tendieron habitualmente a considerar que la racionalidad era una cualidad difícil de alcanzar por un ser humano sometido inicialmente a inclinaciones y pasiones resistentes a la adquisición de una razón que ya Espinosa había definido como una "pasión débil".

La metafísica, entendida como investigación del ser común podría hacer posible, en el campo de la teoría social, explicar la unidad de ejercicio entre la comunidad real y la comunidad ideal de comunicación que logra el consenso social, como el resultado de la unidad subyacente preconstitutiva de la forma y de la materia social, unidad sobre la que comunidad real y comunidad ideal se constituyen como polos de un mismo proceso natural limitado de comunicación. La "limitación comunicativa" aristotélica impide entender la sociedad como constituida de individuos, esto es, de átomos sociales, que, paradójicamente, serían siempre susceptibles de ulteriores divisiones en sus deseos, motivaciones, posibilidades argumentativas, etc., pues la comunidad aristotélica está ya preconstituida en el sujeto mínimo común que es la familia, comunidad natural sin la que no puede entenderse lo humano. El individuo aristotélico no estaría limitado por su deseo, que es indefinido, sino por su naturaleza común, esto es, por su pertenencia natural a una comunidad, a una familia cuyo fin es la ciudad, en tanto que la familia es una condición para la vida, aunque sólo la ciudad es la condición para la vida buena. Para que haya sido posible el triunfo del individualismo formal, que se encuentra en la base ontológica de las teorías éticas que proponen el consenso como norma del bien, ha de haberse arruinado tanto la exigencia de limitación que el ser humano se impone a sus deseos, a su poder. Una vez rotos esos límites, el individuo se siente libre para expandirse en pensamiento y acción, para, más tarde, buscar el modo de recomponer la unidad de lo humano con los fragmentos antropológicos, psicológicos, sociológicos o políticos que han dejado tras de sí los siglos de progreso del Razón. Las teorías ético-políticas que se basan en el diálogo responden a este esfuerzo del individualismo, pero, su renuncia al naturalismo las obliga a trabajar con los únicos medios que pone a su disposición el tejido conceptual formalista, que ha sustituido la igualdad proporcional de los individuos en relación con los fines de la 
ciudad por la identidad absoluta de cada individuo consigo mismo, esto es, con su deseo, y la jerarquía recíproca funcional de los componentes del todo social por el igualitarismo formal e indiferente de agrupaciones azarosas de individuos que finalmente se ven obligados a aceptar la subordinación al poder unívoco del Estado.

La realidad social de las democracias, tal como son de hecho, genera una paradoja que consiste en que unas teoría éticas "consensuales", que tratan de exponer el modo en que puede resultar superflua la intervención directa del Estado para hacer posible la estabilidad social, consiguiendo que la resolución de conflictos pueda autorregularse mediante el diálogo entre los agentes sociales, han acabado por legitimar la aparición de una nueva forma de Estado del bienestar que ha entrado a regular hasta el más mínimo detalle de la vida de los ciudadanos. Con el método del "control preventivo" la administración estatal en las democracias avanzadas trataría de evitar por anticipado cualquier acción que pudiera ir contra el sistema, evitando de este modo tener que recurrir a los tradicionales métodos represivos con los que el Estado ha asegurado la estabilidad social. Y aunque, en principio, podría pensarse que esto es una consecuencia práctica, más o menos indeseable, de unas teorías éticas diseñadas para lograr la identificación de la verdad con el bien, de hecho, en su concepción teórica, estas éticas no parecen tratar adecuadamente la contradicción entre la noción que sostienen de un sujeto racional comunicativo que argumenta de acuerdo con las normas del bien y la verdad, y una realidad social generada por siglos de historia, desde la irrupción de la modernidad, que ha sustentado la constitución de la comunidad humana en las fuerzas de la pasión, del deseo y del temor, como recurso para superar las tendencias disgregadoras del individualismo. La equipolencia de todos los discursos, la igualdad de derecho de todas las reivindicaciones o la obligación administrativa de corregir todos los agravios manifiestan a las claras la ausencia de cualquier "principio objetivo" de cualquier "norma pretendidamente común", en nombre de la cual establecer una jerarquía racional de valores. La sociedad igualitarista no se plantea como objetivo la igualdad en el diálogo racional, sino que parte de la igualdad sentimental de hecho de todos los individuos, de todos los grupos y todas las aspiraciones humanas. Se trata de una forma de antielitismo que no acepta superioridad jerárquica alguna, y que reclama una visión ideológica del mundo adaptada a este modo contrailustrado de entender la igualdad. Esta visión es compartida plenamente por los medios de comunicación "de masas", que en su origen remoto trataron de sustituir la dirección socio-política sobre el pueblo que ejercían las élites ilustradas por una forma de cultura al alcance de las poblaciones de las sociedades democratizadas. Y si lo políticamente correcto se ha ido demostrando como el sistema de ideas 
más adaptado a las sociedades democráticas igualitaristas, multiculturales y victimistas, que son el modelo que se pretende universalizar en nuestra era de la globalización, ha sido en gran medida porque tiene una perfecta correspondencia con el nivel intelectual y moral de los grandes medios de comunicación de masas que representan — si no sustituyen - a una opinión pública a la que se le hace creer que es permanentemente escuchada.

Este sueño de la democracia global tiene, sin embargo, un lado mucho menos radiante del que la propaganda mediática difunde, pues ha servido también para afianzar una forma de Estado neoliberal, que oculta sus orígenes tras la declaración de que su objetivo es la "corrección" de las desigualdades, unas desigualdades, sin embargo, que el propio liberalismo capitalista ha contribuido a crear. Resulta, entonces, que un Estado democrático que aparenta ser tan frágil por huir de toda forma de imposición sobre la sociedad, se transforma en un modelo político de una extraordinaria fortaleza. Pues el Estado contemporáneo es cada vez más el espacio sistémico en el que tiene lugar el proceso de retroalimentación entre una sociedad hipersensibilizada que entiende la participación política como la libertad de expresión de los agravios sufridos, unos medios de comunicación que, día a día, crean y amplifican la ideología de lo políticamente correcto, adecuada para las víctimas que todos somos, y una administración estatal cuya principal labor consiste en ir corrigiendo agravios selectivamente, lo que creará nuevos agravios que habrán de ser nuevamente corregidos en un proceso que se puede extender indefinidamente. De este modo, el Estado neoliberal global, que asume la forma de un Estado sistémico del bienestar, se impone hoy, no menos amenazador y despótico que el Leviathán hobbesiano.

\section{REFERENCES}

Llamas Roig, Vicente. "Manifiesto Fundacional Escuela de Metafísica de Madrid”. Carthaginensia, Revista de Estudios e Investigación. 35 (2019): 251252.

Francisco León Florido

Departamento de Filosofía y Sociedad

Facultad de Filosofía

Universidad Complutense de Madrid Ciudad Universitaria, Plaza Menéndez Pelayo, s/n 28040 Madrid (España)

https://orcid.org/0000-0001-6157-0400 